carbo-hydrates so far as possible being excluded. Under this regimen the patient improved at once. The next day the thirst was gone, and only sixty onnces of urine were passed, of sp. gr. 1035. After one week the daily excretion was about sixty-five ounces of sp. gr. 1030, still containing sugar, though in greatly diminished amount. He was then given half a grain of codeia three times daily immediately after meals. Two days later, nine days from the commencement of treatment, the sugar entirely disappeared. Since that date (March 19th) the urine has remained absoEutely free from sugar, and the patient has completely regained health and strength. The codeia was first reduced on Nay 7th to one grain and on the 21st to half a grain daily. In the first week of June the diet was gradually celaxed, until by the end of that month the patient returned to his ordinary food and the codeia.was left off altogether.

A very similar case to the above was reported in 'THE LANCET of April 2nd, 1892, by Mr. Hoysted. Acute diabetes came on a. week after influenza and disappeared entirely upon treat. ment by dieting and codeia. As regards the pathology little can be said. When first seen the case appeared to be one which might terminate fatally in a comparatively short time, and if untreated probably would have done so. The attack Collowed very closely upon influenza, and, taking the other case into consideration, it is impossible to resist the inference that it was a sequela of it. It is possible that several such cases may have occurred during the recent epidemics. On the other hand, influenza occurring in a diabetic patient does not necessarily agoravate the disease. In one case of severe siabetes, at a time in which by careful dieting and treatment by codeia the urine was kept free from sugar, it remained so during an attack of influenza and for several weeks afterwards, although during the febrile period a milk diet was orincipally used. It is probable that diabetes following inGuenza, though very acute in its onset and doubtless if unsreated rapidly tending to a fatal termination, yet differs from che ordinary form in its special amenability to treatment.

Ipswich.

\section{AN UNCOMMON CAUSE OF DEAFNESS.}

BY C. F. Williamson, M.R.C.S., L R.C.P. Lond. \&c.

I THINK the following case of deafness is of sufficient interest to be published in THE LANCET on account of its cerity.

Recently I was asked to see a boy aged six years who was suffering from neuralgia, otorrhcea and deafness. On examination there were a slight discharge, not offensive, assuing from the external meatus, total deafness, and a dark bject filling up the passage. No history could be extracted of anything having been introduced into the ear. All intempts at a second examination were repulsed, and as I was some distance from my house I desisted, intending to give an anæsthetic the following day. Next morning, on examination, I found a foreign body presenting at the ireatus, which was easily removed by a bent probe, and rroved to be a blowfly complete except for its wings. When the mother of the child saw the fly she said that vighteen months previously she attended a sale, taking her son with her. While there he caught a fly by its wings and sept constantly holding it up to his ear to hear it buzz. After a short time the wings became detached and the fly crawled into his ear. All that night the boy cried with earache, but next day was free from pain and had remained so until a fiew days before my advice was sought.

Horley.

\section{WCCENTRICITY OF PUPILS DUE TO FAULTY} POSITION OF HEAD AND EYES.

\section{By C. Price TANNer, L.R.C.P. LoNd., M.R.C.S.}

G. H. C- a , aged eleven, was admitted into the Worcester County and City Lunatic Asylum on March 1st, 1887, and died at the beginning of the present year. He was an idiot from birth. No abnormality of eyes was noted at the sime of admission. During the last two years of his life we following condition was observed repeatedly. His head was always flexed on to his chest, and as a rule the eyes were closed. When he opened his eyes the distance between vhe edges of the lids did not exceed from one-fourth to threeeighths of an inch. The eyes were directed downwards and forwards. The lateral movements were apparently normal, perhaps a little restricted in range. There was no convergent or divergent squint. Vertical movement of the eyes was nerer observed. On raising the upper lid only the upper half of the cornea and iris was visible, and the iris was found to be unequally contracted, its opening; although circular, being nearer the upper than the lower margin of the cornea. The lower part of the cornea could only be seen by depressing the lower eyelid. The iris reacted sluggishly to light, but the eccentricity of the pupil was always present. The same condition obtained in both eyes, and persisted after death, being distinctly visible, though to a slightly less degree, sixty-six hours after death. I think it probable that the position of the iris was due to the faulty position of the head, coupled with the downward strabismus, which would allow light to act only upon the upper part of the iris.

Powick, near Worcester.

\section{A}

\section{HOSPITAL PRACTICE, BRITISH AND FOREIGN.}

Nulla autem est alia pro certo noscendi via, nisi quamplurimas et morporum et dissectionum historias, tum aliorum tum proprias collectas borum et dissectionum historias, tum aliorum tum proprias collectas
habere, et inter se comparare.-Morgati De Sed. et Caus. Lorb.,

\section{MIDDLESEX HOSPITAL.}

CASE OF LACERATED WOUND OPENING THE AXILLA, SIMULATING A STAB.

(Under the care of Mr. HuLKE.)

TrAT in instances of injury, particularly those which are attended with breach of continuity of the surface of the body, much assistance towards attaining a correct appreciation of the circumstances of the wound will frequently be derived from inspecting the patient's clothes is a truism recognised by all but yet neglected by many. An examination of the clothes should be a matter of routine, at the earliest opportunity, and where it is probable that a case may become the subject of legal inquiry it can never wisely be omitted. The following is an example of its utility.

W. C- aged twenty-seven, a carman, was admitted into Founder ward on Nov. 7th, 1892, with a wound two inches long, vertically dividing the integument and the deeper structures of the upper part of the anterior fold of the axilla and passing deeply downwards into this space. Its edges were slightly frayed and bruised, suggestive of the wound having been inflicted with a blunt knife. The patient himself, dazed and confused, had no distinct recollection of the way in which he had incurred the injury, but those who brought him to the hospital said that he had fallen off a van and he had, it was thought, struck his left shoulder against the splinter bar. An inspection of his shirt confirmed this account. Widely stained by a large effusion of blood, the material of the shirt corresponding to the situation of the wound was found to be quite entire, thus conclusively disproving a stab. The wound was flushed with a mercuric perchloride solution, covered with a dry antiseptic dressing and the arm secured to the side. On Nov. 21st he was dismissed with the wound healed. Here, not improbably, the wound may have been inflicted by the blunt edge of the iron stud attached to the ends of the splinter bar for securing the traces, and the toughness of the material of the shirt prevented its being torn. Where, however, the impact of the body and the implement is very great, large pieces may be torn out of a garment and deeply buried in a wound, and this not merely in gunshot injuries, but in those resulting from the accidents of civil life. Thus a lad was admitted into the Middlesex Hospital with a lacerated wound in the floor of the right axilla; he was said to have spiked himself on a paling in falling from a window on to the pavement. A few days later an abscess formed on the shoulder, which enclosed a rag of linen nearly as large as the palm. This was found to be a piece of his shirt, the presence of which in the wourd might 